
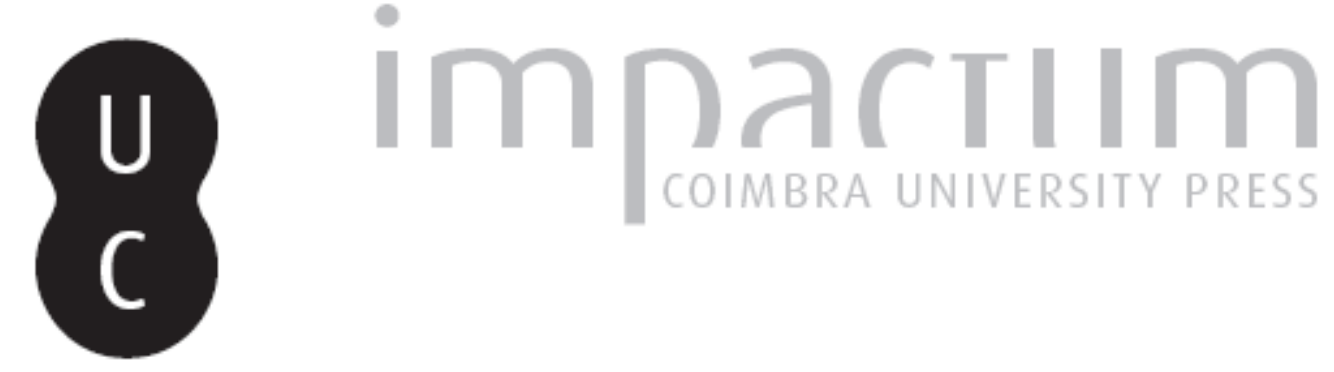

\title{
[Recensão a] Factor Five: Transforming the Global Economy through $80 \%$ Improvements in Resource Productivity Ernst von Weizsäcker, Karlson 'Charlie' Hargroves, Michael H. Smith, Cheryl Desha e Peter Stasinopoulos
}
Autor(es):
Nicolau, Mariana

Publicado por: CEDOUA

URL

persistente:

URI:http://hdl.handle.net/10316.2/40028

DOI:

DOI:https://doi.org/10.14195/2182-2387_25_7

Accessed : $\quad$ 26-Apr-2023 11:45:20

A navegação consulta e descarregamento dos títulos inseridos nas Bibliotecas Digitais UC Digitalis, UC Pombalina e UC Impactum, pressupõem a aceitação plena e sem reservas dos Termos e Condições de Uso destas Bibliotecas Digitais, disponíveis em https://digitalis.uc.pt/pt-pt/termos.

Conforme exposto nos referidos Termos e Condições de Uso, o descarregamento de títulos de acesso restrito requer uma licença válida de autorização devendo o utilizador aceder ao(s) documento(s) a partir de um endereço de IP da instituição detentora da supramencionada licença.

Ao utilizador é apenas permitido o descarregamento para uso pessoal, pelo que o emprego do(s) título(s) descarregado(s) para outro fim, designadamente comercial, carece de autorização do respetivo autor ou editor da obra.

Na medida em que todas as obras da UC Digitalis se encontram protegidas pelo Código do Direito de Autor e Direitos Conexos e demais legislação aplicável, toda a cópia, parcial ou total, deste documento, nos casos em que é legalmente admitida, deverá conter ou fazer-se acompanhar por este aviso.

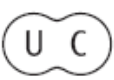




\section{RevCEDöUA}

N. ${ }^{0} 25$ _ Ano XIII_ 1.10

> Doutrina

Breve apontamento sobre a natureza jurídico-lributária da 'taxa'

sobre as lâmpadas de baixa eficiência energética

José Eduardo F. Dias

Joana Duarte Costa

A criaç̦ão de AMPs nas zonas da plataforma conlinental situadas além das 200 mn: Direito do Mar, CPLP e experiência portuguesa pós- 'hainbow'

Marta Chantal Ribeiro

A responsabilidade civil do estado brasileiro perante os riscos para o meio-ambiente do sequestro geológico de carbono

Lucas de Lima Carvalho

Da admissibilidade de meios extrajudiciais de resolução de confititos em matéria ambiental e urbanística - experiências presentes, possibilidades futuras

Cátia Marques Cebola

Concurso de Ideias e Estudos sobre a Revisão da Lei de Bases do Ambiente

Ana Cristina Vieira

> Jurisprudência

A desconsideração do nexo causal na responsabilidade civil ambiental

Neylene Fonseca

Recensões

Faclor Five: Transforming the Global Economu through 80\%

Improvements in Resource Productivity

Mariana Nicolau

Dossier

Ecossistemas de profundidade, AMPs oceânicas, plataforma continental além das 200mn e pioneirismo português

Marta Chantal Ribeiro

Ricardo Serrão Santos

Abstracts > Últimas Aquisições Bibliográficas

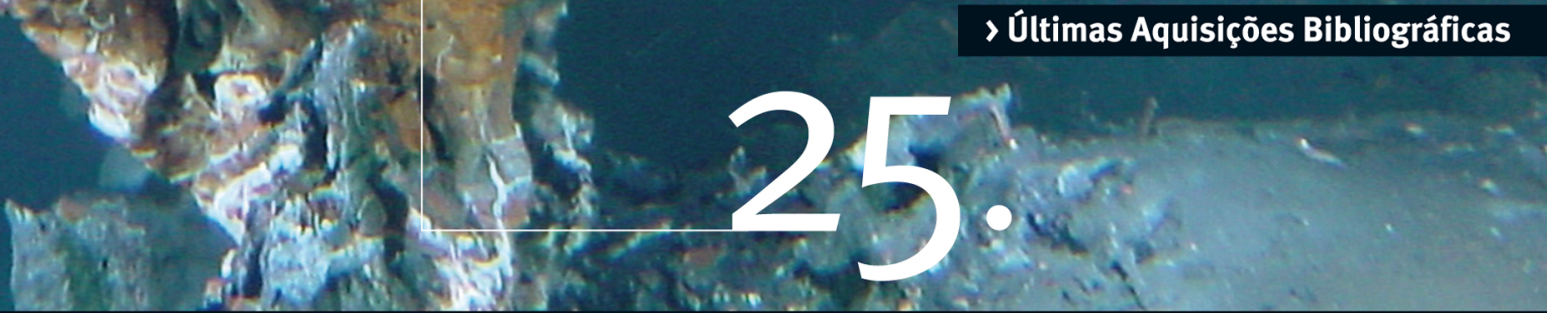

Revista do Centro de Estudos de Direito do Ordenamento, do Urbanismo e do Ambiente Urbanism, Territorial Order and Environment Studies Center Law Review 


\section{Factor Five: Transforming the Global Economy through $80 \%$ Improvements in Resource Productivity Ernst von Weizsäcker, Karlson 'Charlie' Hargroves, Michael H. Smith, Cheryl Desha e Peter Stasinopoulos Earthscan, London, 2009}

No cenário atual em que a humanidade é confrontada, mais do que nunca, com o desafio de mudar a maneira como se relaciona com o ambiente, a obra em apreço tece os fios condutores ao desenvolvimento sustentável de forma incrivelmente inspiradora, sem deixar de ser realista.

Factor Five é o mais novo informe ao Clube de Roma, organização internacional fundada com o propósito de analisar e tornar público problemas humanos cruciais, e cuja primeira publicação é o memorável trabalho "Os limites do crescimento", de 1972. Consiste em uma atualização do livro "Factor Four: Doubling Wealth - Halving Resource Use", de 1997, e é resultado de uma parceria entre Ernst von Weizsäcker e The Natural Edge Project (TNEP), uma associação australiana de engenheiros e cientistas dedicados à pesquisa em matéria de sustentabilidade.

Ante a constatação de que a crescente pressão humana sobre o ambiente - pressão esta materializada tanto pela extração e utilização insana dos componentes ambientais quanto pelo retorno incalculável dos mais variados tipos de resíduos - atinge hoje níveis tão alarmantes que colocam em risco iminente a existência do planeta Terra tal como o conhecemos e, por conseguinte, a própria existência humana, a obra conclama-nos a agir.

O livro está dividido em duas partes. A Parte I, apontada como o núcleo da obra, desempenha com rigor, e de forma muito didática, o papel de demonstrar a viabilidade técnica e financeira de tornar realidade a afirmação estampada no subtítulo do livro. Ela é escrita pelos membros do TNEP e destina-se à apresentação de oportunidades e exemplos práticos que permitem uma melhoria na produtividade e eficiência dos recursos ambientais da ordem de, pelo menos, $80 \%$ (ou seja, uma produtividade 5 vezes maior, daí o título da obra), e que tornam possível, portanto, reduzir a pressão humana sobre o ambiente a, no mínimo, 1/5 (um quinto) do patamar atual. Referidas oportunidades variam desde a retomada de antigas técnicas agrícolas ou de construção civil até as mais sofisticadas tecnologias em estudo ou já disponíveis no mercado, e são apresentadas em conjunto no seio de estudos que analisam diferentes sectores da economia, a partir de uma abordagem sistematizada ("a whole system approach") dos mesmos, com o objetivo de alcançar a maior produtividade dos recursos e o menor impacto ambiental possíveis, para proporcionar serviços de mesma qualidade ou ainda melhores.

Os estudos setoriais apresentados por Factor Five focam especificamente nos sectores econômicos que respondem pelas maiores frações da totalidade de utilização de energia, água e materiais e de emissão de gases de efeito estufa, no mundo: construção civil (Capítulo 2), 
indústria pesada - aço e cimento (Capítulo 3), agricultura (Capítulo 4) e transportes (Capítulo 5). Em cada um dos estudos, após conferir ao leitor um panorama do contexto atual em que se insere o sector econômico em análise (percentuais de utilização de recursos ambientais e de emissão de resíduos nas maiores economias mundiais, principais técnicas utilizadas atualmente e problemas socio-ambientais decorrentes de tais práticas), são apresentadas as propostas de eficiência e produtividade com base em estratégias extraídas do $4^{\circ}$ Relatório do Painel Intergovernamental sobre Mudanças Climáticas (IPCC) e que redundam em um total de 8: (a) eficiência energética, (b) substituição de combustível, (c) recuperação de calor e energia, (d) energia renovável, (e) mudança de matéria-prima, (f) mudança do produto, (g) eficiência dos materiais e (h) redução dos gases de efeito estufa distintos do $\mathrm{CO}_{2}$.

Embora aparentemente ousada, a Parte I da obra é fonte de inestimável inspiração e esperança, uma vez que apresenta dados concretos e demonstrações práticas, e não apenas teóricas, de condutas rentáveis (ainda que a longo prazo) capazes, de fato, de transformar sectores econômicos inteiros, envolvendo os âmbitos público e privado, tanto nos países desenvolvidos quanto naqueles ainda em desenvolvimento, a abarcar bens e construções residenciais e industriais já existentes (por meio de reformas e reequipamentos) ou que ainda estão por vir, com vista a promover a eficiência e uma melhor qualidade de vida.

A Parte II da obra, por seu turno, é desenvolvida com maestria por Ernst von Weizsäcker, que assume o desafio de propor medidas para "fazer acontecer", para tornar realidade o desenvolvimento sustentável. O primeiro provável questionamento que nos assalta é: mas não bastam as propostas apresentadas na primeira parte do livro e que, inclusive, já são realidade em diversas partes do mundo? Com generosas doses de realismo, Weizsäcker constata que, a despeito de intensas mobilizações científicas e acadêmicas no sentido de oferecer meios para promover a sustentabilidade - dentre as quais se destaca o livro Factor Four - e, ainda, inobstante diversos exemplos atuais de governos, empresas e pessoas que já adotam práticas sustentáveis, o consumo de energia e componentes ambientais tem crescido incessantemente e, em diversos casos, de forma exponencial. Tal fato é atribuído, sobretudo, ao crescimento constante da população mundial, ao papel cada vez mais tímido dos Estados na condução de assuntos econômicos (principalmente no que diz respeito ao controle dos preços dos recursos ambientais e ao incentivo a práticas sustentáveis) e à cultura da insuficiência e do consumismo.

Em face dessas constatações, Weizsäcker considera insuficiente limitar-se ao campo da técnica e da tecnologia se o objetivo é, de fato, atingir um desenvolvimento sustentável. Nesse sentido, propõe que a abordagem sistematizada e abrangente que permeia a transformação da eficiência nos sectores econômicos deve expandir-se ainda mais para englobar também a transformação do papel dos Estados e do próprio estilo de vida dos homens. É tomado por esse propósito que o autor discute, ao longo da Parte II da obra, temas como: a atuação reguladora do Estado (Capítulo 6); os contributos de instrumentos econômicos em matéria ambiental (Capítulo 7); o dilema do "efeito de repercussão" ("rebound effect"), referente à problemática de que o aumento da produtividade dos recursos nem sempre vem acompanhada da redução (mas do aumento) do consumo de recursos ambientais (Capítulo 8); as potencialidades de uma reforma fiscal ecológica de longo prazo (Capítulo 9); a necessidade de um equilíbrio estável entre bens públicos e privados (Capítulo 10); e as limitações da cultura do consumo e da insuficiência, momento em que o autor, propositadamente, mais levanta questionamentos e provoca reflexões do que propriamente oferece respostas prontas e acabadas (Capítulo 11). 
Ainda que Factor Four e Factor Five tragam em seu bojo uma mensagem semelhante, qual seja, a de que é possível elevar consideravelmente a produtividade dos recursos (com avanços da ordem de $75 \%$ e $80 \%$, respectivamente) de forma rentável, há dois pontos na relação entre ambas as obras que merecem ser destacados.

Em Factor Four, Ernst von Weizsäcker, em co-autoria com Hunter Lovins e Amory Lovins, ofereciam 50 exemplos para quadruplicar a produtividade energética e dos materiais. Como Weizsäcker mesmo afirma em Factor Five, a obra anterior centrou-se na análise dos principais exemplos de técnicas e tecnologias isoladas. Diferentemente, Factor Five propõe uma abordagem holística e sistematizada de sectores inteiros da economia, para, a partir de uma visão do todo, neles identificar criticamente as possibilidades de eficiência e produtividade. Referida "abordagem do sistema como um todo", inclusive, como mencionado acima, ultrapassa os limites da tecnologia para ganhar terrenos na discussão do papel do Estado e dos homens.

É preciso não olvidar-nos, porém, de que os mais impressionantes exemplos de produtividade de energia e de recursos trazidos por Factor Four, a destacar o "hiper-carro" e o "edifício biológico" que é sede do Rocky Mountain Institute (EUA), já carregavam em sua gênese, como ponto de partida para tornar possível a sua "invenção", uma análise do sistema (do carro, do edifício) como um todo, para possibilitar a identificação de oportunidades de produtividade que desencadeariam outras oportunidades mais, e que, portanto, permitiria um produto final ainda mais eficiente do que as oportunidades tomadas isoladamente. Em outras palavras, ainda que por meio da análise de tecnologias isoladas, Factor Four já levantava a bandeira da necessidade de lançar mão de uma visão sistematizada do objeto de estudo para torná-lo eficiente.

O segundo ponto a ser destacado diz respeito ao fato de que, embora ambas as obras tenham a preocupação de explicitar a relação custo-benefício e o carácter lucrativo das oportunidades de produtividade e eficiência propostas, o argumento ambiental parece ganhar mais peso em Factor Five. A necessidade de rever determinadas práticas é imperiosa em virtude do excesso de pressão que as mesmas exercem sobre o ambiente. E não era para ser diferente, dado que hoje vivenciamos níveis ainda mais absurdos de degradação ecológica e a iminência de catástrofes ambientais não nos permite esperar décadas e mais décadas de condutas irresponsáveis e despreocupadas.

Talvez a pertinência do título da obra em apreço seja ainda maior do que se notaria à primeira vista. Mais do que promover apenas um fator de eficiência, de produtividade, Factor Five busca atingir um fator de transformação de conceitos, prioridades e estilos de vida. Esta obra imperdível está parcialmente disponivel online, no endereço www.factorfiveonline.info, em que é possível obter acesso a alguns capítulos do livro, bem como a estudos setoriais extras. 